\title{
Tensões Representacionais nos Discursos dos alunos durante a realização das atividades experimentais de Física
}

\section{Representational Tensions in students' Discourses while completing experimental Physics activities}

\author{
Luís da Silva Campos ${ }^{1}$ \\ https://orcid.org/0000-0001-6973-3630 \\ Mauro Sérgio Teixeira de Araújo ${ }^{2}$ \\ https://orcid.org/0000-0002-0088-8973
}

\begin{abstract}
Resumo: Baseada na teoria dos códigos de Basil Bernstein, Andréia de Oliveira propôs o conceito de Tensão nos Discursos para designar as descontinuidades entre os diferentes discursos presentes na prática educacional, marcadas pelas contradições, rupturas e dilemas gerados pelos espaços que separam as categorias de discursos especializados. Neste artigo analisamos as tensões representacionais manifestadas nos discursos dos alunos quando realizavam atividades experimentais em um laboratório didático de Física. Essas tensões se caracterizam por mostrar as contradições, rupturas, dilemas, conflitos e incertezas quando os dados provenientes das atividades experimentais são confrontados com os conceitos apresentados nas aulas teóricas, evidenciando um isolamento no discurso interno à Física. Verificamos que os estudantes manifestaram essas tensões nos momentos em que representaram as medidas com suas incertezas, transformaram as unidades de medidas e suas incertezas e ao registrarem o número de casas decimais e de algarismos significativos das medidas e de suas incertezas.
\end{abstract}

Palavras-chave: Análise de discurso. Estudante universitário. Experiência de laboratório. Ensino de física.

\begin{abstract}
Based on the theory of codes by Basil Bernstein, Andréia de Oliveira presents the concept of Tension in Discourses to designate the discontinuities between the different discourses present in educational practice, characterized by contradictions, ruptures and dilemmas that are generated by spaces that separate the categories of specialized discourses. In this paper, we analyze the representational tensions manifested in students' discourses when they performed experimental activities in a didactic physics laboratory. These tensions are characterized by showing the contradictions, ruptures, dilemmas, conflicts and uncertainties when data coming from experimental activities are contrasted with the concepts present in theoretical classes, thus causing an isolation in the internal discourse about physics to become evident. We found that the students revealed these tensions at the moments when they represented the measures with their uncertainties, when they transformed units of measurement and their uncertainties, and when they registered the number of decimal places and of significant algorithms for the measurements and their uncertainties.
\end{abstract}

Keywords: Discourse analysis. University student. Laboratory experiments. Physics teaching.

\footnotetext{
${ }^{1}$ Associação Paulista de Educação e Cultura, Guarulhos, SP, Brasil.

${ }^{2}$ Universidade Cruzeiro do Sul (UNICSUL), Centro de Ciências Exatas e Tecnológicas, São Paulo, SP, Brasil.

E-mail:mauro.araujo@cruzeirodosul.edu.br
} 


\section{Introdução}

Para elaborar o conceito de Tensão nos Discursos, Oliveira (2010) baseou-se em alguns elementos da teoria dos códigos de Bernstein (1990, 2000), como a recontextualização pedagógica referente ao processo em que um discurso pedagógico é selecionado e movido de um contexto primário de produção do conhecimento para um contexto secundário da reprodução do discurso, gerando uma complexa transformação, ao modificar um discurso original para um discurso virtual ou imaginário (BERNSTEIN, 1990).

Neste percurso ocorre um processo onde o discurso original é abstraído da sua base social, posição, e relação de poder. Neste sentido, as disciplinas escolares como Física, Matemática, Química, entre outras, contemplam discursos especializados que foram recontextualizados no momento em que houve deslocamento do seu contexto original para o contexto secundário da prática pedagógica (OLIVEIRA, 2010). Assim, os discursos presentes nos livros didáticos e em outros materiais pedagógicos do Ensino de Física foram movidos do contexto da produção do conhecimento dessa Ciência para o contexto da sua reprodução, através do princípio da recontextualização pedagógica.

As dúvidas, dilemas, angústias e conflitos apresentados pelos alunos podem se manifestar em virtude do isolamento existente entre os diferentes discursos presentes na resolução de um problema experimental de Física, trazendo à tona as contradições decorrentes dos vários discursos especializados. Deste modo, este isolamento presente nas disciplinas singulares pode produzir tensões nos discursos dos alunos, que são manifestadas quando eles utilizam conceitos das diferentes disciplinas para resolver problemas experimentais com finalidades pedagógicas. Tendo em vista as características das atividades experimentais realizadas pelos estudantes envolvidos nesta investigação e os fenômenos presentes durante essas atividades acadêmicas, elaboramos a seguinte questão de pesquisa que direcionará a análise apresentada neste artigo: quais são as características das Tensões Representacionais manifestadas nos discursos dos alunos, durante a realização das atividades experimentais em um laboratório didático de Física?

\section{As Finalidades das Diferentes Modalidades de Experimentação}

Ao analisar as funções do laboratório didático de Ciências, Barolli, Laburú e Guridi (2010) nos mostram algumas controvérsias nas concepções de diferentes pesquisadores e destacam que o laboratório didático algumas vezes é utilizado como meio de explorar a relação entre a Física e a realidade. Em outras situações, o laboratório didático é visto como uma estratégia para o desenvolvimento de conceitos e habilidades procedimentais. Existem casos em que o laboratório didático é entendido como um ambiente para problematizar diferentes domínios do conhecimento, enquanto em outros casos ele é visto como um lugar privilegiado para desenvolver trabalhos em equipe. Há aqueles que defendem o laboratório didático por ser uma estratégia motivadora para o ensino de Ciências ou como um ambiente cognitivo e fértil para se aprender Ciências.

Essas controvérsias estão relacionadas com a visão de aprendizagem e com o processo de construção do conhecimento representados pelos pesquisadores. Assim, entendemos que esta polêmica sempre existirá, visto que os pesquisadores entendem e defendem pontos 
de vista diferentes no que tange ao papel que as atividades experimentais desempenham no Ensino de Ciências, em concordância com Barolli, Laburú e Guridi (2010). Os trabalhos de Silveira e Ostermann (2002) e de Laburú (2003) criticam a visão indutivista da Ciência, uma vez que esta visão "[...] imagina os cientistas olhando o mundo sem idéias 'a priori', extraindo relações e generalizações a partir da coleta e registro de dados e de observações objetivas" (KIRSCHENER, 1992 apud LABURÚ, 2003, p. 235). Esses autores também criticam a utilização dos laboratórios didáticos de forma hipotético-dedutiva e lembram que não existe “[...] uma necessária conexão funcional epistemológica entre fazer Ciência e os métodos pelos quais ela é aprendida e principalmente ensinada para os não cientistas". Para eles "fazer Ciência é distinto de entender e aprender Ciência, que é principalmente distinto de aprender algo sobre a Ciência" (LABURÚ, 2003, p. 236).

As críticas apresentadas por Laburú (2003) estão em sintonia com o modelo da recontextualização pedagógica de Bernstein (1990, 2000), segundo o qual a Ciência é ensinada por meio de um discurso que foi recontextualizado de um contexto primário da produção do discurso, para um contexto secundário da sua reprodução, empregando-se para isto o princípio da recontextualização pedagógica. Dessa forma, o discurso da Ciência que é ensinada nas escolas e universidades guarda pouca relação com o discurso da Ciência que é produzida nos centros e institutos de pesquisa e universidades.

Não defendemos a concepção de que somente podemos utilizar o Método Científico para construir conhecimento em Ciência, nem que esse método segue uma rígida rotina de observação, formulação de hipóteses, experimentação, medição, estabelecimento de relações, conclusões e proposição de leis e teorias científicas, aspectos criticados por vários pesquisadores, entre eles Moreira e Ostermann (1993), Silveira e Ostermann (2002), Borges (2002) e Barolli, Laburú e Guridi (2010). Ao contrário, entendemos que o conhecimento científico se constrói através de complexas relações entre conceitos teóricos e dados experimentais (BORGES, 2002). Em alguns casos os dados experimentais servem de suporte para analisar determinados fenômenos à luz de conceitos teóricos. Em outras situações, os conceitos teóricos são utilizados para analisar os dados provenientes da experimentação.

Nesse sentido, Borges (2002) defende a existência de uma intrincada relação entre as dimensões teórica e empírica quando se trata das atividades experimentais com propósitos pedagógicos. Por um lado, os conceitos teóricos orientam e dão suporte para as análises dos dados experimentais e, por outro, os dados experimentais reforçam ou questionam as teóricas podendo provocar mudanças ou adaptações nos modelos tomados como referência. Entendemos que o laboratório didático pode cumprir diferentes funções e ser utilizado com diferentes finalidades, como nos mostra Araújo e Abib (2003). Deste modo, iniciamos as atividades experimentais com uma proposta de laboratório programado, contendo roteiros com procedimentos bem detalhados. Isto se justifica pelo fato da maioria dos alunos não apresentar familiaridade com os procedimentos experimentais, sendo este encaminhamento também defendido por Ribeiro, Freitas e Miranda (1997).

As atividades experimentais que selecionamos possuem o potencial de proporcionar aos alunos grande interação com o professor e com seus colegas e uma forte associação dos dados obtidos nos experimentos com os conceitos teóricos estudados nas salas de aula. A pesquisa de Borges (2002) se alinha com essa proposta ao destacar que o importante não é só proporcionar aos alunos a manipulação de objetos e artefatos concretos, visto que essas atividades 
devem estimular o envolvimento dos estudantes na busca de respostas ou soluções para as questões colocadas. Assim, com o propósito de analisar os fenômenos relacionados com a tensão no discurso manifestada pelos alunos durante a realização das atividades experimentais, desenvolvemos um conjunto de atividades com roteiros fechados e estruturados, caracterizado como laboratório programado por Moreira e Levandowski (1983).

Todas as investigações científicas têm como base teorias que lhes fornecem suporte. A identificação e o conhecimento dos fenômenos que nos cercam só são possíveis quando utilizamos uma ou mais teorias capazes de oferecer suporte à nossa análise. Porém, uma boa teoria científica deve oferecer condições objetivas para nossa interpretação. Nas palavras de Bernstein (1990, p. 98, tradução nossa), "uma teoria deveria gerar os critérios para a sua avaliação, os contextos necessários para sua exploração, os princípios para sua descrição e as regras para sua interpretação". Partindo do pressuposto de que todas as pessoas entendem o mundo a partir de teorias, esse autor nos chama a atenção para a necessidade de deixarmos clara a nossa posição, sem nos escondermos atrás de modelos no momento em que necessitamos explicitar a nossa voz.

\section{Código, Classificação e Enquadramento na Teoria de Basil Bernstein}

Código foi definido por Bernstein (1990, p. 14, tradução nossa) como "um princípio regulativo, tacitamente adquirido, que seleciona e integra: (a) significados relevantes, (b) formas de realização e contexto evocadores". Desse ponto de vista, um código é um princípio que regula as relações entre contextos e dentro de um contexto específico. Neste sentido, podemos entender um código como um princípio regulador que se encontra na base dos sistemas de mensagens, podendo ser relacionado com o currículo, a pedagogia ou a avaliação. Por currículo, Bernstein entende como conhecimento válido e aceito socialmente, pedagogia como transmissão válida das informações relacionadas com o conhecimento e a avaliação é entendida como a realização válida desse conhecimento (MAINARDES; STREMEL, 2010).

O discurso pedagógico é definido por Bernstein (1990) como um princípio que se apropria de outros discursos com o objetivo de colocá-los em uma relação mútua, visando à transmissão e aquisição de informações. Nesse sentido, o discurso pedagógico não possui um discurso específico, ele se constitui de um princípio que coloca outros discursos em uma relação mútua. Com o objetivo de entender os princípios da comunicação responsáveis pelas relações de poder e de controle presentes na prática pedagógica, Bernstein apresenta dois conceitos centrais da sua teoria: a classificação e o enquadramento (OLIVEIRA, 2010). Santos (2003) discute o conceito de classificação utilizado por Bernstein, enfatizando que esse pensador define classificação no sentido diferente do usual. Ele a utiliza para se referir às relações entre as categorias e não para distinguir um atributo ou um critério de uma categoria. A classificação é utilizada para descrever a relação de poder e controle daquilo que é ensinado (MAINARDES; STREMEL, 2010).

Assim, a relação entre sujeitos, por exemplo, professor e alunos, entre discursos, por exemplo, Matemática, Física, Química, etc., entre outras, são denominadas de classificação e se referem ao conteúdo da comunicação na categoria, ou seja, aquilo que pode ser dito (OLIVEIRA, 2010). Em outras palavras, é a classificação que define o conteúdo da comunicação que é legítimo dentro de um determinado contexto. Entendemos que podem existir 
diferentes discursos que dizem respeito à importância e ao papel da Física, assim como atividades com diferentes abordagens pedagógicas, convivendo no mesmo ambiente acadêmico. Esses discursos podem apresentar isolamentos internos capazes de produzir as Tensões nos Discursos dos alunos, sendo relevante salientar que esses isolamentos fazem parte da nossa investigação.

Cabe ressaltar que estamos diante de dois fenômenos distintos: de um lado o isolamento entre as disciplinas pedagógicas que podemos chamar de isolamento externo e do outro o isolamento entre os discursos presentes em uma mesma disciplina pedagógica que denominaremos de isolamento interno. Para a nossa análise essa distinção é importante, pois os estudantes realizam atividades didáticas experimentais de Física ao mesmo tempo em que têm contato com discursos legítimos produzidos nas outras disciplinas e, ainda, com discursos provenientes das aulas teóricas de Física. Portanto, o isolamento se faz presente nas duas situações que discutimos anteriormente.

O enquadramento se refere à relação dentro das categorias e representa as formas de comunicação legítimas que compõem a prática pedagógica, ou seja, não se refere ao que pode ser dito, mas como pode ser dito (OLIVEIRA, 2010; SANTOS, 2003). A definição de enquadramento e sua relação com o transmissor e o adquirente são apresentadas por Bernstein (1990). É o enquadramento que "determina o controle sobre a seleção, sequência, ritmos e critérios da comunicação" (BERNSTEIN, 1990, p. 36, tradução nossa). O enquadramento estabelece a hierarquia das práticas comunicativas, a velocidade em que as informações são transmitidas, o que pode ser dito nessa comunicação e os critérios utilizados pelo transmissor e pelo adquirente para que a comunicação possa produzir um texto legítimo dentro de um contexto social.

Bernstein (1990) nos mostra que classificação e enquadramento podem operar de forma completamente independente. Esse enquadramento proposto por Bernstein se refere ao controle sobre a comunicação entre alunos e entre aluno e professor, priorizando as formas de comunicação consideradas legítimas em cada ambiente educacional. Existem diferentes discursos presentes na prática pedagógica que se manifestam por meio de textos produzidos oralmente ou por escrito. Bernstein $(1999,2000)$ apresenta dois tipos de discursos denominados discurso horizontal e discurso vertical. O discurso horizontal se refere ao conhecimento do senso comum presente no dia a dia das pessoas, enquanto o discurso vertical se refere ao conhecimento oficial legitimado e reproduzido no interior das escolas, universidades, ou outras instituições de ensino (OLIVEIRA, 2010).

Para a realização das atividades pedagógicas no Ensino de Física precisamos mover os discursos presentes no contexto da produção (pesquisa e desenvolvimento da Física) para o contexto da reprodução (prática pedagógica). A seleção do que deve ser movido e como essas informações serão deslocadas entre estes dois contextos são determinados pelos discursos “consolidados socialmente na prática pedagógica" (OLIVEIRA, 2010, p. 25). O processo pelo qual um discurso é deslocado do contexto de produção para o de reprodução é definido por Bernstein $(1990,2003)$ como um princípio recontextualizador. O discurso pedagógico é o responsável por esse deslocamento. Nele há uma transformação no discurso original, de forma que a base social de sua prática é eliminada.

A pesquisa aqui relatada abordou a formação de alunos ingressantes no Ensino Superior em cursos de Engenharias. Portanto, nossa pesquisa se desenvolveu em um contexto 
completamente diferente daquele que Oliveira (2010) utilizou para a realização da sua pesquisa. No entanto, entendemos que a categoria teórica Tensões nos Discursos, construída a partir de princípios fundamentais da teoria dos códigos de Bernstein (1990, 1999, 2000, 2003) é de fundamental importância para analisarmos os fenômenos observados durante os momentos em que os alunos realizam as atividades práticas e constroem seus relatórios.

\section{Procedimentos Metodológicos}

Essa investigação se caracteriza como pesquisa qualitativa, segundo a qual grande parte dos fenômenos presentes na realidade são socialmente construídos (MOREIRA, 2011). Preocupamo-nos com a compreensão dos fenômenos sociais que ocorrem em ambientes acadêmicos, com as finalidades de ensino e aprendizagem. Nosso olhar foi direcionado para os fenômenos que ocorrem nos discursos dos alunos durante a realização das atividades experimentais, levando em conta a perspectiva destes estudantes e através da participação e intervenção direta do professor.

Obtivemos os dados a partir do ambiente natural, ou seja, do laboratório didático onde as atividades experimentais foram realizadas. $\mathrm{O}$ instrumento principal de coleta de dados da investigação foi constituído pelo gravador de áudio, que esteve presente durante a realização dos experimentos. Cada turma que participou do laboratório de Física I era dividida em vários grupos de alunos. Nessa pesquisa analisamos os dados provenientes de apenas um grupo de cada turma, sendo cada grupo constituído por 3 alunos. Desse modo, nossa observação envolveu 15 alunos, distribuídos em 5 grupos de estudantes pertencentes a 5 turmas distintas, sendo que nestes grupos figuravam alunos que pretendiam cursar diferentes modalidades de Engenharia. Apresentaremos neste artigo apenas a análise de partes das transcrições dos áudios produzidos pelos 5 grupos selecionados durante a realização de um dos experimentos, para identificar e caracterizar as Tensões Representacionais observadas nos discursos dos estudantes.

Nossa pesquisa é descritiva, pois estamos mais interessados nos processos do que nos resultados ou produtos. Nesta abordagem consideramos o significado do que acontece nas interações entre professores e alunos, conferindo a elas uma importância vital. Essas características reforçam a premissa de que a nossa investigação é de caráter qualitativo, conforme nos mostram Bogdan e Biklen (1994). Neste sentido, os fenômenos, os alunos e o professor envolvidos no processo da investigação não estão separados, de maneira que durante a realização das atividades educacionais todos estão envolvidos e o professor (pesquisador) está interessado em compreender os fenômenos que se manifestam nos processos de ensino e de aprendizagem.

Realizamos a análise dos dados tendo como inspiração a linguagem de descrição elaborada por Bernstein (2000). A linguagem de descrição apresenta a possibilidade de permitir uma relação dialética reflexiva entre os conceitos presentes na linguagem interna e os dados empíricos que se pretende analisar (MORAIS; NEVES, 2007).

Bernstein (2000) caracteriza a linguagem de descrição como um esquema de tradução pelo qual uma linguagem é transformada em outra, sendo caracterizada como linguagem de 
descrição interna aquela que diz respeito à teoria com seus conceitos e modelos. Por sua vez, a linguagem de descrição externa é associada aos princípios e modelos derivados da linguagem de descrição interna, utilizada para entender, analisar e descrever os fenômenos estudados.

A importância da linguagem de descrição está na relação dialética da linguagem de descrição interna, que orienta os atos de reconhecimento, classifica as relações entre conceitos e forma a lógica de textos especializados, com o modo específico em que um fenômeno é descrito, através de um modelo teórico que guia um segundo conjunto de conceitos chamado de linguagem de descrição externa (SHALEM, 2004). Assim, entendemos que a categoria teórica Tensão nos Discursos criada por Oliveira (2010) pode ser caracterizada como uma linguagem de descrição externa, construída e elaborada a partir de elementos presentes na teoria dos códigos de Bernstein (1990, 2000), que representa a linguagem de descrição interna.

Quando analisamos as transcrições dos áudios obtidos durante a realização das atividades experimentais verificamos que os estudantes apresentavam dúvidas, dilemas, angústias e conflitos no momento em que precisavam representar as medidas e suas incertezas, quando necessitavam transformar as unidades das medidas e das suas incertezas, quando construíam os modelos pictóricos para representar os fenômenos, no momento em que necessitavam utilizar os modelos da Física e da Matemática para resolver os problemas da Física, quando necessitavam entender o significado do processo de medição e na forma adequada de coleta dos dados.

A partir dessas observações criamos um conjunto de categorias de tensões, sendo uma delas denominada de Tensões Representacionais e que envolve as dúvidas, dilemas, angústias e conflitos relacionados com as representações das incertezas experimentais, com as representações das unidades de medidas, com as transformações das unidades de medidas e com as representações dos modelos pictóricos. As Tensões Conceituais estão relacionadas com a utilização dos modelos teóricos da Física, o entendimento e a utilização dos conceitos matemáticos e o significado dos parâmetros físicos envolvidos nas medidas. As Tensões Procedimentais podem ocorrer durante a realização das montagens dos experimentos, na calibração dos instrumentos de medidas e na forma adequada de coletar os dados.

Propomos, ainda, a categoria denominada de Tensões Epistemológicas, envolvendo as dúvidas, os dilemas, as angústias e os conflitos que podem estar associados com o entendimento do processo de construção do conhecimento gerado pela Ciência e de estruturação do pensamento científico, com o entendimento do papel da experimentação frente a este processo e, ainda, com a compreensão da Ciência como uma atividade humana, bem como as dúvidas e incertezas relacionadas com suas descobertas. Esta categoria não foi elaborada a partir da análise dos dados coletados junto aos alunos, tendo em vista a natureza das atividades experimentais realizadas sendo, entretanto, sugerida na medida em que as atividades experimentais possibilitem discutir e evidenciar aspectos da Natureza da Ciência e do processo de construção do conhecimento científico.

Entendemos a importância da abordagem experimental que discute a construção dos conhecimentos científicos e seus procedimentos, principalmente por meio do viés histórico, filosófico e social. Entretanto, cabe destacar que não priorizamos esse debate ao longo da coleta de dados da nossa pesquisa por se tratar de intervenções realizadas em uma instituição que apresenta uma visão pragmática dentro dos cursos de Engenharias, oferecendo pouca abertura para este tipo de debate, em que pese a sua inegável relevância. 


\section{Características da pesquisa realizada e dos fenômenos analisados}

Durante a realização das atividades experimentais existem situações em que ocorrem as tensões nos discursos dos alunos (OLIVEIRA, 2010; OLIVEIRA; BARBOSA, 2011; SILVA; OLIVEIRA, 2012). No caso deste trabalho, estas tensões surgiram quando os estudantes realizavam as montagens dos experimentos, coletavam os dados provenientes das atividades experimentais e analisavam esses dados para construírem seus relatórios. Percebemos que estas situações podem gerar diferentes Tensões nos Discursos dos alunos, sendo as mesmas classificadas como: (a) tensão na representação das incertezas experimentais; (b) tensão na representação das unidades de medidas; (c) tensão nas transformações das unidades de medidas; (d) tensão na representação dos modelos pictóricos; (e) tensão na utilização dos modelos teóricos da Física; (f) tensão na utilização dos conceitos matemáticos; (g) tensão no significado do processo de medição; (h) tensão na realização das montagens dos experimentos; (i) tensão na calibração dos instrumentos; (j) tensão na maneira de coletar os dados; (k) tensão no processo de construção da Ciência e de estruturação do pensamento científico; (l) tensão no entendimento do papel da experimentação frente ao processo de construção do conhecimento científico; e, (m) tensão no entendimento da Ciência como atividade humana, envolvendo dúvidas e incertezas acerca das suas descobertas e de algumas características, tais como neutralidade e salvacionismo.

Ao analisarmos os documentos observamos que dois ou mais itens das tensões nas representações das incertezas experimentais, nas representações das unidades de medidas, nas transformações das unidades de medidas e nas representações dos modelos pictóricos surgiram ao mesmo tempo, sendo muito difícil distinguir estes tipos de tensões nos discursos. Por esse motivo, criamos uma categoria de tensão nos discursos em que essas quatro formas podem ser agrupadas. Chamamos essa nova categoria de Tensões na Representação dos Dados Experimentais, ou simplesmente Tensões Representacionais.

Por outro lado, a tensão na utilização dos modelos teóricos da Física, a tensão na utilização dos conceitos matemáticos e a tensão associada ao significado dos processos de medições também surgiram em alguns instantes isoladamente, em outros elas apareciam ao mesmo tempo. Em alguns casos os alunos apresentaram dúvidas, incertezas, conflitos e dilemas na escolha do modelo teórico que iriam utilizar para analisar os dados provenientes dos experimentos, em outros momentos observamos grandes conflitos quando os alunos realizavam as operações matemáticas necessárias para a análise desses dados ou no instante de entenderem o significado dos parâmetros físicos envolvidos nas medidas realizadas. Para esses casos criamos uma categoria que engloba essas três tensões e denominamos de Tensões Conceituais.

Por fim, algumas tensões nos discursos estavam relacionadas com a maneira correta de se utilizar um instrumento de medição ou na sequência correta de apresentação dos dados obtidos. Neste sentido, os alunos apresentaram tensões nos discursos durante o processo de montagem dos arranjos experimentais, nas calibrações dos instrumentos utilizados para coletar os dados, na maneira correta de se utilizar os instrumentos de medidas de forma a obter o valor mais próximo possível do valor verdadeiro da medida, ou na maneira correta de se registrar os dados que foram obtidos. Denominamos a categoria que engloba essas tensões de 
Tensões Procedimentais. O quadro 1 sintetiza estes conjuntos de tensões e indica as possíveis subcategorias de tensões para cada categoria representada.

Quadro 1 - Categorias de tensão nos discursos dos alunos

\begin{tabular}{|l|l|}
\hline $\begin{array}{c}\text { Categorias das Tensões } \\
\text { nos Discursos }\end{array}$ & \multicolumn{1}{c|}{ Subcategorias das tensões para cada categoria } \\
\hline Representacionais & $\begin{array}{l}\text { (a) Tensão na representação das incertezas experimentais; } \\
\text { (b) Tensão na representação das unidades de medidas; } \\
\text { (c) Tensão nas transformações das unidades de medidas; } \\
\text { (d) Tensão na representação dos modelos pictóricos; }\end{array}$ \\
\hline Conceituais & $\begin{array}{l}\text { (e) Tensão na utilização dos modelos teóricos da Física; } \\
\text { (f) Tensão no entendimento e utilização dos conceitos matemáticos; } \\
\text { (g) Tensão no significado dos parâmetros físicos das medidas; }\end{array}$ \\
\hline Procedimentais & $\begin{array}{l}\text { (h) Tensão na realização das montagens dos experimentos; } \\
\text { (i) Tensão na calibração dos instrumentos; } \\
\text { (j) Tensão na forma com que os dados são coletados; }\end{array}$ \\
\hline Epistemológicas & $\begin{array}{l}\text { (k) Tensão no entendimento do processo de construção da Ciência e de } \\
\text { estruturação do pensamento científico; } \\
\text { (l) Tensão no entendimento do papel da experimentação frente ao } \\
\text { processo de construção do conhecimento científico; } \\
\text { (m) Tensão no entendimento da Ciência como uma atividade humana, } \\
\text { envolvendo dúvidas e incertezas acerca das suas descobertas e de suas } \\
\text { características. }\end{array}$ \\
\hline
\end{tabular}

Fonte: elaborado pelos autores.

Neste artigo analisaremos apenas as situações em que as Tensões nos Discursos dos alunos estão associadas com a representação dos dados experimentais, que surgiram nas atividades práticas do laboratório didático de Física, utilizando os dados presentes nas transcrições de apenas um experimento, visando caracterizar o fenômeno aqui apresentado. Fizemos essa opção por conta da limitação de espaço e também pelo fato de que as abordagens relacionadas com as Tensões Conceituais e Procedimentais deram origem a outro artigo intitulado Tensões Conceituais e Procedimentais nos discursos dos alunos durante as atividades experimentais de Física, já aceito para publicação e que se encontra no prelo (CAMPOS; ARAÚJO, 2019).

\section{Análise dos dados obtidos na Pesquisa}

Apresentaremos os dados da terceira experiência realizada pelos estudantes, na qual eles precisavam trabalhar com as componentes das forças e utilizar as condições de equilíbrio de rotação e de translação para garantir que uma haste metálica permanecesse em repouso na horizontal. Para a realização desta atividade, os alunos dispunham de uma haste metálica conectada a um suporte vertical por meio de um pino livre, conforme mostra a figura 1. 
Figura 1 - Haste em equilíbrio

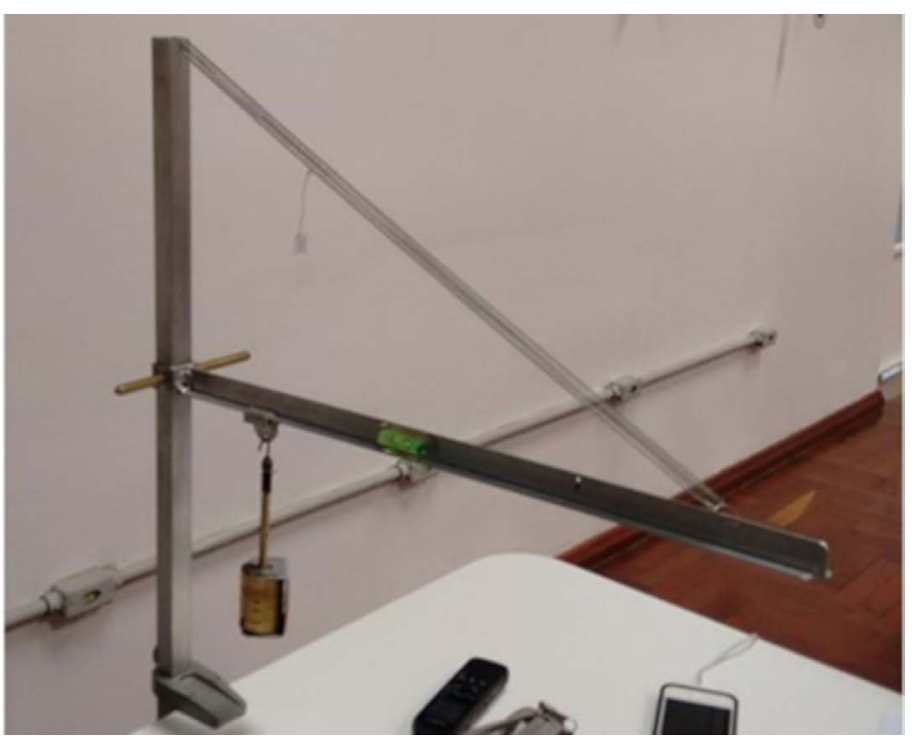

Fonte: foto de arquivo dos autores.

Figura 2-DCL da haste e da carga

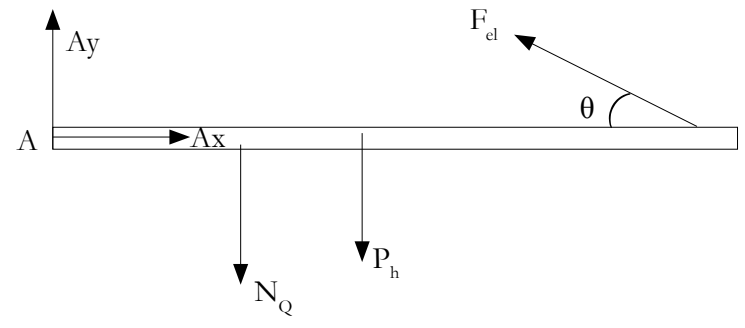

Fonte: elaborado pelos autores.

As forças que atuavam nesta haste eram o seu peso, uma força exercida por uma carga cujo valor deveria ser escolhido pelos alunos, uma força exercida por uma mola deformada que conectava a haste ao suporte vertical e a força de reação que o pino exercia sobre ela. Os alunos deveriam variar a posição da carga até que a haste ficasse em equilíbrio na posição horizontal, o que era verificado através de uma bolha de nível. Apresentamos na figura 2 um diagrama de corpo livre (DCL) para a haste e para a carga.

Quando analisamos a transcrição do áudio dos alunos do grupo $\mathrm{G}_{1}{ }^{3}$, percebemos que a interação entre os alunos e destes com o professor acontecia de forma permanente. Além

\footnotetext{
${ }^{3}$ As letras A e $G$ que aparecem no texto e nas transcrições se referem aos alunos e aos grupos respectivamente. Nesse sentido, $A_{1} G_{1}$ refere-se ao aluno denominado 1 que pertence ao primeiro grupo, chamado de grupo 1 .
} 
disso, as dúvidas quanto ao número de casas decimais na representação das medidas surgiram com pouca profundidade. Logo no início da atividade uma aluna perguntou para outra quantas casas decimais deveria ter a medida, o que foi respondido corretamente pela segunda aluna. Percebemos que as tensões que surgiram nos discursos dos estudantes que compunham esse grupo, relativas às representações de unidades das medidas e das incertezas, às transformações das unidades e de como representariam as incertezas se mostraram superficiais, conforme apresentadas na transcrição a seguir.

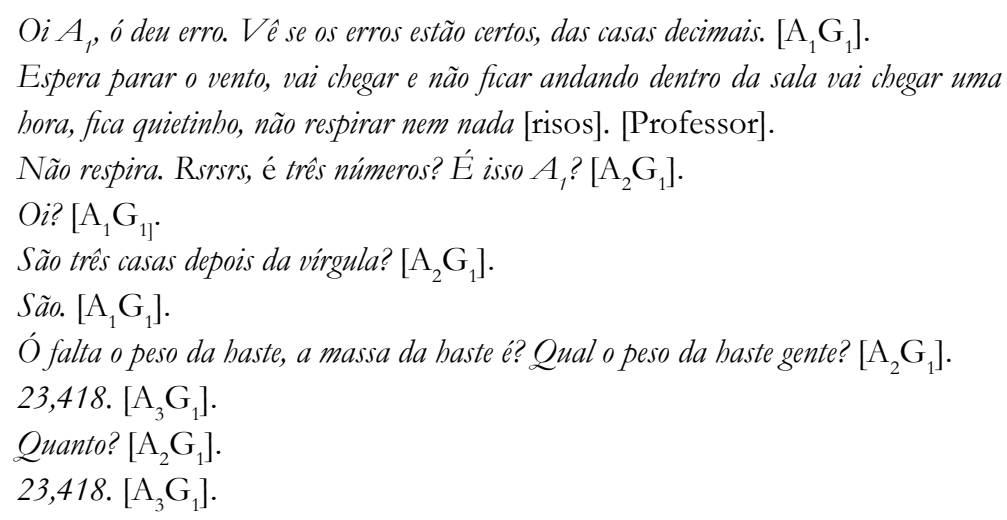

É importante destacar que as interações dos alunos nesse grupo eram permanentes. Eles discutiam a melhor maneira de realizar a atividade e como iriam registrar os dados. Os impasses que apareceram foram resolvidos de forma harmoniosa e em algumas situações eles pediram o auxílio do professor para solucionar a dúvida. Percebemos que a execução das atividades era organizada pela aluna $A_{1}$ em função do seu desprendimento, da sua iniciativa e do seu envolvimento, porém suas sugestões e opiniões sempre foram discutidas pelos outros integrantes do grupo, sem que seus colegas as aceitassem passivamente. Essas interações possibilitaram profundas discussões sobre a maneira correta de coletar, registrar e analisar os dados provenientes dos experimentos. As transcrições a seguir nos mostram as interações dos estudantes deste grupo.

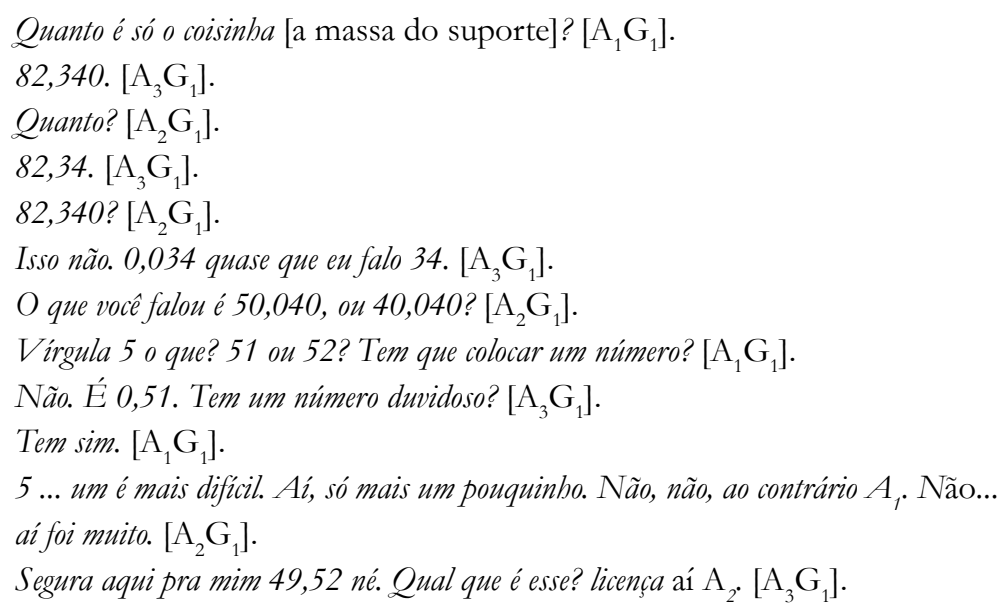


As poucas dúvidas, incertezas, dilemas e conflitos nas indicações das medidas, na representação dos dados com suas devidas incertezas e na transformação das unidades de medidas, juntamente com suas incertezas, podem indicar que as Tensões Representacionais que surgiram com maiores intensidades nas duas atividades anteriores estavam sendo superadas.

Os alunos do Grupo $G_{2}$ mostraram dúvidas, incertezas e dilemas na maneira correta de representar as medidas obtidas, no número de casas decimais e nas incertezas, bem como na maneira correta de transformar as unidades de medidas e de suas incertezas para representar corretamente esses dados em seus relatórios, sinalizando a ocorrência de Tensões Representacionais nos seus discursos.

Um dos alunos do grupo $G_{2}$ faltou no dia dessa atividade. Apenas as outras duas alunas fizeram esse experimento, de forma que só identificamos as falas de dois estudantes no áudio que gravamos. Essas alunas mostraram uma grande interação no que diz respeito à execução das atividades que faziam parte desse experimento. Elas discutiram para chegarem na melhor maneira de coletar os dados e, além disso, cada aluna participou ativamente de cada etapa da execução do trabalho. A transcrição a seguir ilustra algumas interações observadas:

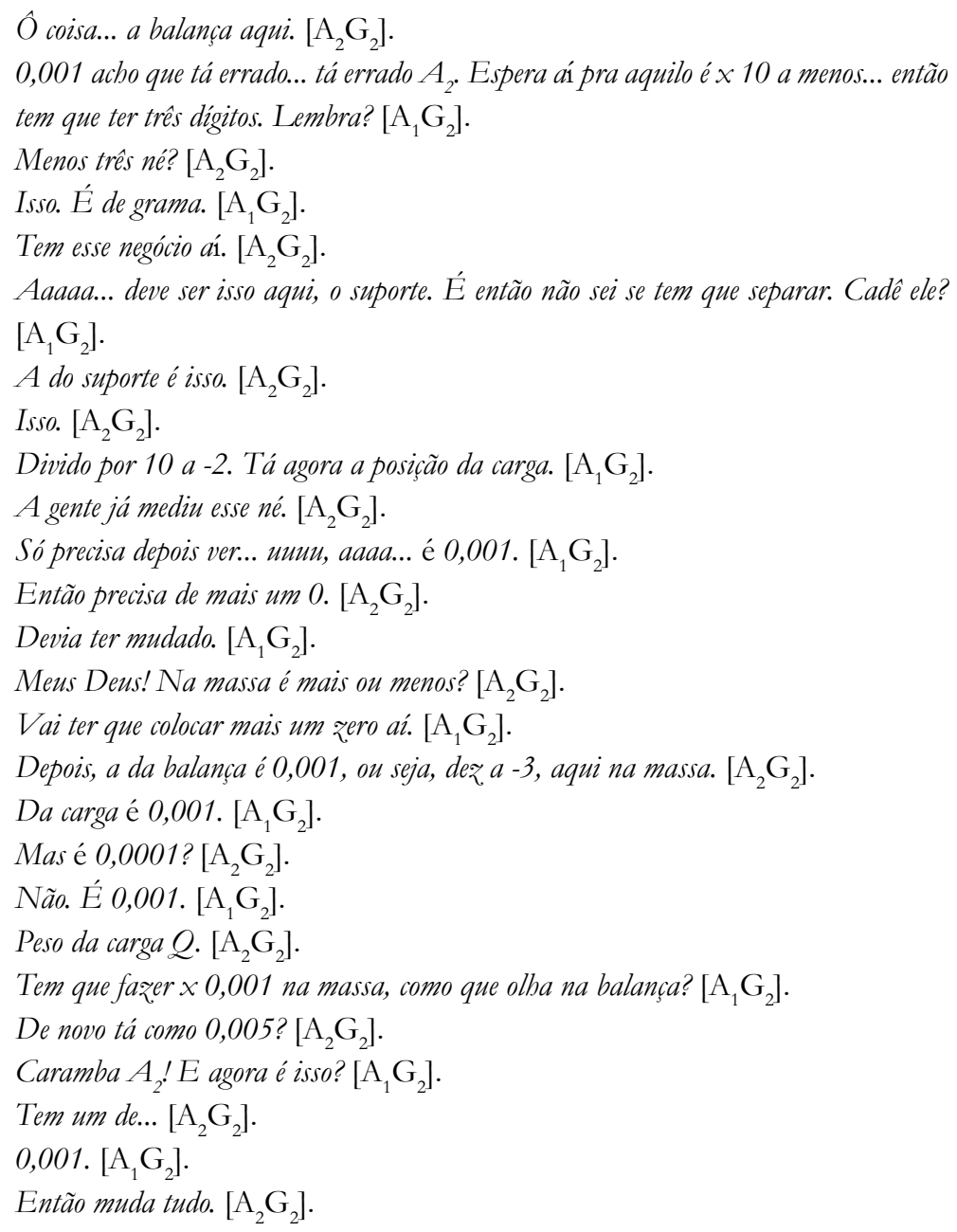


Aí que não era a canetinha. $\left[\mathrm{A}_{1} \mathrm{G}_{2}\right]$.

Que canetinha? Tá a lápis. Esse também é 0,001, aqui tem que ter o 3 né? $\left[\mathrm{A}_{2} \mathrm{G}_{2}\right]$.

É. $\left[A_{1} G_{2}\right]$.

Mais ou menos e igual. $\left[\mathrm{A}_{2} \mathrm{G}_{2}\right]$.

O comprimento é o outro não é $0,01 \cdot\left[\mathrm{A}_{1} \mathrm{G}_{2}\right]$.

É $0,05, e ́ e, 05 .\left[\mathrm{A}_{2} \mathrm{G}_{2}\right]$.

É $\operatorname{sim}\left[\mathrm{A}_{1} \mathrm{G}_{2}\right]$.

Peso da haste e esse o número de casas decimais, mano, tô perdida, como que a gente fez nesse? $\left[\mathrm{A}_{2} \mathrm{G}_{2}\right]$.

É A.S.? $\left[\mathrm{A}_{1} \mathrm{G}_{2}\right]$.

Tá vendo, por causa do sinal não é? Foi o que a gente fe : $\left[\mathrm{A}_{2} \mathrm{G}_{2}\right]$.

Percebemos que as duas alunas discutiram sobre a maneira adequada de transformar as unidades das medidas e das grandezas, assim como a forma correta de representá-las. Notamos ainda que as sugestões de cada elemento do grupo eram debatidas de forma que, após as discussões e dos convencimentos, a informação era registrada no relatório. Não percebemos que a opinião de um integrante era acatada sem questionamentos como vimos em outros grupos. Como o impasse na maneira correta de representar os dados e transformar as unidades das medidas e de suas incertezas persistia, as alunas recorreram ao professor para que pudesse avaliar a opinião de cada uma e dizer quem estava correta. O professor fez questionamentos para que as estudantes se lembrassem dos conceitos trabalhados e discutidos nas aulas anteriores e para que se sentissem mais seguras no momento de escrever os seus relatórios.

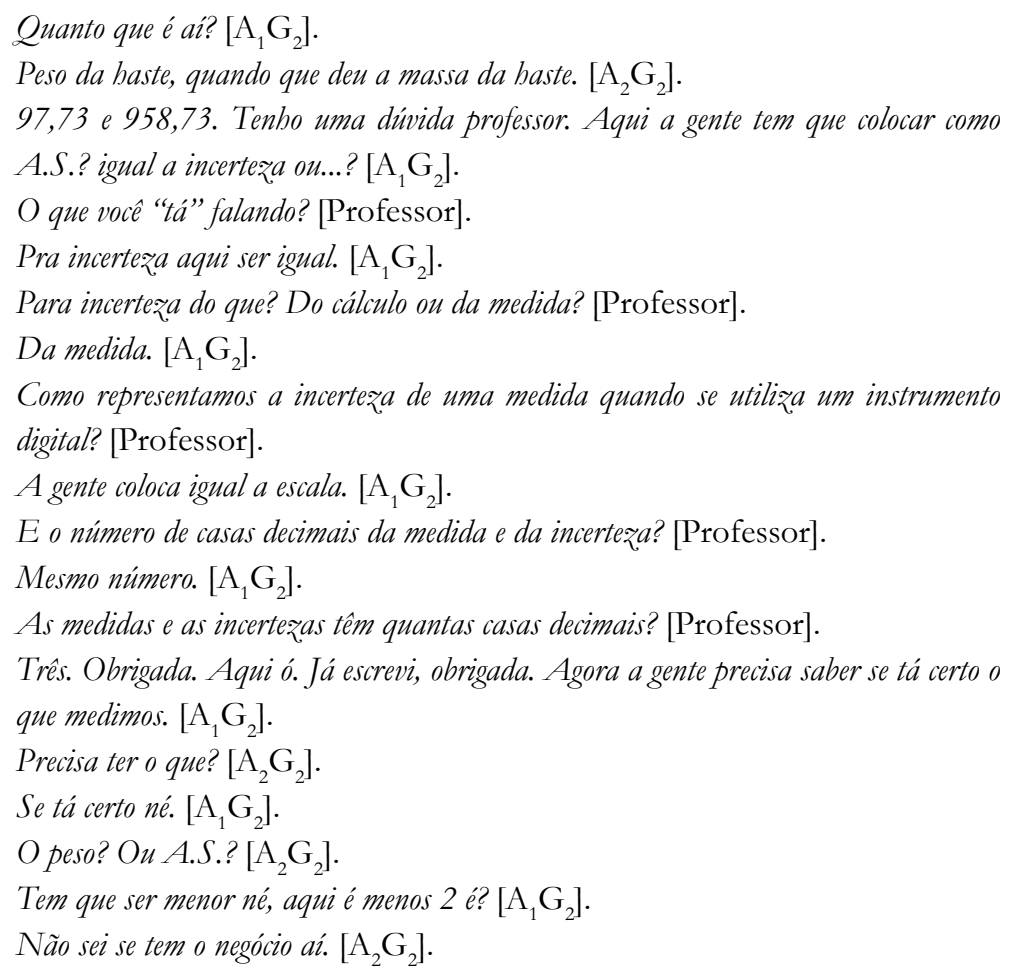


Precisa passar pra metro? $\left[\mathrm{A}_{1} \mathrm{G}_{2}\right]$.

Acho que não, né? Vai ficar quanto? $\left[\mathrm{A}_{2} \mathrm{G}_{2}\right]$.

Cateto oposto 24 sobre 45. Agora não sei se tem que ser em metro ou centímetro. $\left[\mathrm{A}_{1} \mathrm{G}_{2}\right]$.

As estudantes precisavam utilizar o triângulo retângulo mostrado na figura 1 para calcular o ângulo entre a mola deformada e a haste horizontal. Para isso, mediram o cateto oposto a este ângulo, representado pela distância entre o pino de articulação da haste vertical e sua extremidade superior e o cateto adjacente a este ângulo, formado pela distância entre o pino de articulação e o ponto em que a mola conecta a haste horizontal.

Percebemos que os problemas experimentais enfrentados foram importantes para que as Tensões nos Discursos (OLIVEIRA, 2010; OLIVEIRA; BARBOSA, 2011; SILVA; OLIVEIRA, 2012) envolvendo a representação das medidas e suas unidades, as incertezas e transformações das unidades de medidas e as unidades das incertezas, fossem evidenciadas e também para que fosse possível às estudantes manifestarem seus pontos de vista na tentativa de superar essas tensões.

Verificamos também que as dúvidas, os conflitos, os dilemas e as incertezas, caracterizando as Tensões Representacionais apresentadas pelos alunos desse grupo durante a realização desta atividade estavam associados com os valores corretos das incertezas padrões, com a maneira correta de representar as medidas e suas respectivas incertezas no que diz respeito ao número de algarismos significativos e, ainda, ao número de casas decimais utilizadas. Essas tensões são causadas pelo isolamento interno do discurso da disciplina Física uma vez que esses assuntos são abordados apenas durante as atividades experimentais, mostrando o distanciamento entre os discursos presentes nessas atividades e aqueles que encontramos nas aulas teóricas.

No terceiro grupo os estudantes apresentaram confusões na representação do número de casas decimais das medidas comparado com o número de casas decimais das incertezas. Quando analisamos os áudios gravados, percebemos que o número de algarismos significativos é mencionado, mas as afirmações sobre o zero ser ou não algarismo significativo são contrárias aos valores mencionados após o processo de medição.

Isso, agora mede aí, deixa eu medir aqui 49,5 centímetros, a massa. Aaah e o comprimento da mola estendida é 49,5? $\left[\mathrm{A}_{2} \mathrm{G}_{3}\right]$.

Pera aí, o comprimento da mola. Mas tá em nivel isso? Sorria aí pra foto $A_{2}\left[\mathrm{~A}_{1} \mathrm{G}_{3}\right]$. Se liga 1,000. 0 zero não é A.S.? [ $\left.\mathrm{A}_{2} \mathrm{G}_{3}\right]$.

O zero à esquerda não é A.S. Posso tirar, pra ver a mola? Sem o comprimento da mola com carga, já fizeram ou não? $\left[\mathrm{A}_{1} \mathrm{G}_{3}\right]$.

Notamos que não existiu uma discussão que possa indicar que os alunos refletiram no momento de anotarem os dados no que diz respeito ao número de algarismos significativos e ao número de casas decimais da medida e de sua incerteza. Os dilemas, as dúvidas, as incertezas e angústias, quando surgiam, eram rapidamente solucionados através da opinião de um colega do grupo, sem uma reflexão mais profunda dos demais. Esse padrão se repetiu quando os estudantes foram transformar as unidades de medidas de massa. A opinião de um integrante era prontamente aceita sem maiores discussões e sem pedido de ajuda para o professor. 
Não precisa pôr, ele já tá falando. $\left[\mathrm{A}_{3} \mathrm{G}_{3}\right]$.

Sim, mais precisa colocar pô! O peso é em newtons a massa é em quilograma. $\left[\mathrm{A}_{2} \mathrm{G}_{3}\right]$.

Tá. Tá. Mas isso eu ponho depois, "mais" eu "tô" falando o erro é 0,05. É aqui, falta ó... ah... Não tá certo? $\left[\mathrm{A}_{3} \mathrm{G}_{3}\right]$.

Apesar da clara confusão apresentada pelo aluno sobre incertezas dos instrumentos de medidas, não identificamos conflitos e dúvidas por parte dos outros integrantes e que pudessem levar a uma discussão mais profunda da escala dos instrumentos de medidas, suas resoluções e como consequência a maneira correta de representar as incertezas nas medidas. Também não identificamos pedido de ajuda ao professor, o que nos indica que o professor como parceiro mais capaz nessa atividade não foi reconhecido pelos estudantes, ou eles nem perceberam que tinham dúvidas sobre a coleta e representação dos dados com suas respectivas incertezas. Esta situação indica que a ausência da tensão e a posterior busca de superação da mesma são fatores que contribuíram para que a aprendizagem não ocorresse conforme se esperava.

Ao analisarmos os áudios gravados do grupo $G_{4}$, percebemos que as discussões entre os seus integrantes se concentraram nas transformações de unidades de gramas para quilogramas e na incerteza da balança digital. Eles não mostraram dúvidas sobre quando era necessário ou não representar as incertezas e nem mostraram dúvidas e angustias quanto ao número de casas decimais das medidas e de suas incertezas, como mostramos a seguir.

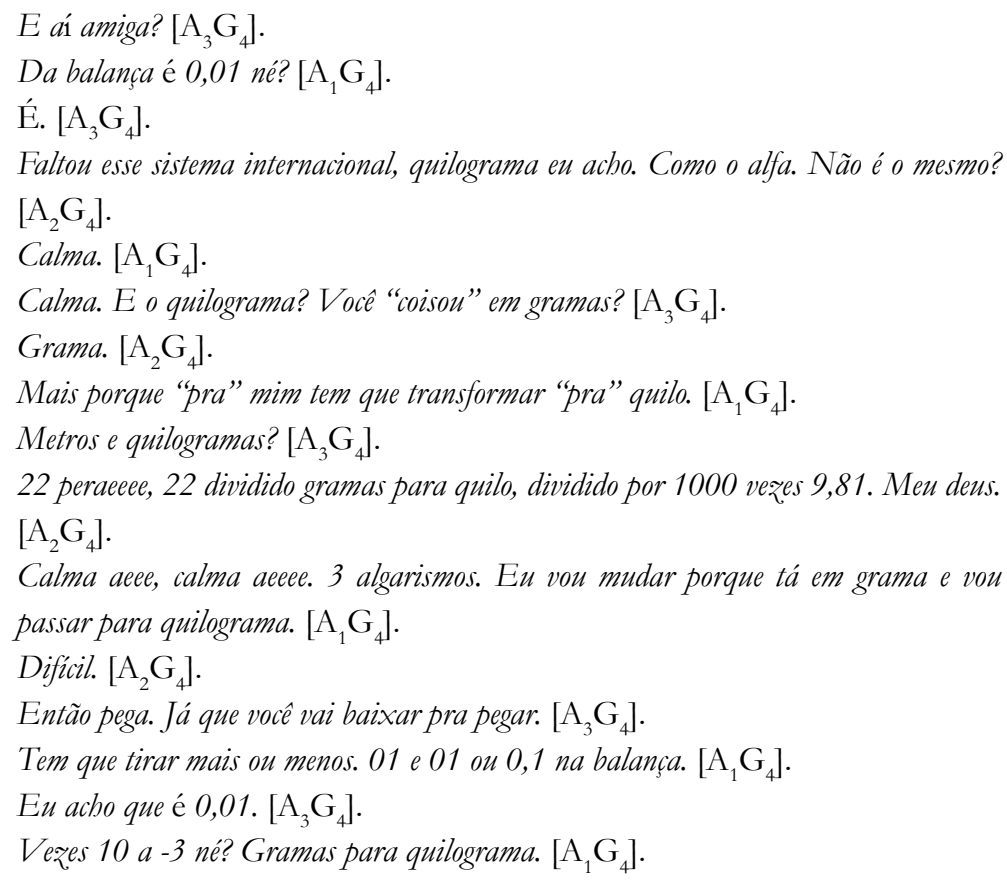

Percebemos que os alunos do grupo $G_{4}$ interagiram muito mais do que os estudantes do grupo $G_{3}$ durante o experimento e na construção dos relatórios. Houve discussões quando surgiram dúvidas e incertezas na forma de representar a unidade de medida e fazer as suas transformações, sendo resolvidas entre os aprendizes, sem solicitar ajuda do professor. 
Observamos que os estudantes se preocuparam em escrever todas as medidas com suas incertezas e transformaram as unidades das medidas e das incertezas, de $\mathrm{cm}$ para $\mathrm{m}$ e de $\mathrm{g}$ para $\mathrm{kg}$ de maneira correta. No entanto, com exceção da massa do suporte deslizante, em todos os outros casos, o número de casas decimais da medida não coincidia com o número de casas decimais da sua incerteza.

Verificamos que a representação das medidas com o mesmo número de casas decimais das incertezas não constituía uma dúvida que figurou entre os integrantes desse grupo nessa atividade. Isso fez com que as Tensões Representacionais relacionadas com este item não se manifestassem e, por isso, os estudantes não tiveram oportunidade de discutir a maneira mais adequada de fazer a representação e nem pedir a ajuda do professor nesse quesito. Desta forma, os erros da representação das medidas e das suas incertezas com o mesmo número de casas decimais não foram cometidos após discussões que mostrassem conflitos, dúvidas, dilemas e incertezas que caracterizariam as Tensões Representacionais.

As Tensões Representacionais mostradas nas falas dos alunos desse grupo estavam relacionadas às identificações das incertezas padrões dos instrumentos de medidas, devido ao isolamento do discurso interno da Física (discurso experimental versus discurso teórico), uma vez que está identificação é característica apenas das atividades experimentais. Já as Tensões Representacionais associadas às transformações das unidades de medidas e de suas incertezas estão associadas com o isolamento do discurso das disciplinas singulares (BERNSTEIN, 2003), uma vez que nas disciplinas de Geometria Analítica e Cálculo não há geralmente preocupação com unidades de medidas e transformações dessas unidades.

Quando analisamos o áudio gravado com alunos do grupo $G_{5}$, verificamos que um estudante associou a incerteza da medida com o erro produzido pela calculadora, porém seu colega mencionou que a calculadora não era o instrumento que produzia a incerteza. Causou estranheza o fato que o valor da incerteza mencionada não correspondia a nenhum instrumento utilizado nesse experimento. De imediato eles perceberam a necessidade de transformar o valor da massa de grama para quilograma, como mostra a transcrição a seguir.

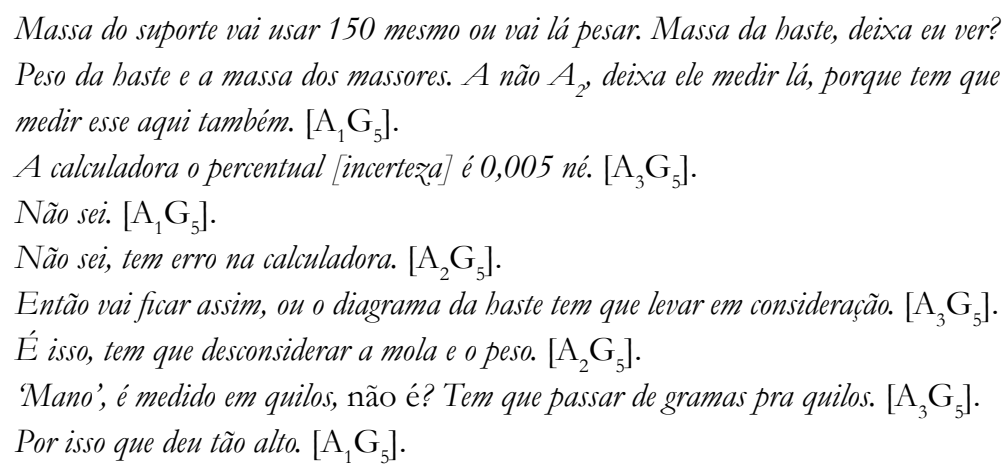

Os alunos desse grupo perceberam que também precisavam transformar a unidade de medida de comprimento de $\mathrm{cm}$ para $\mathrm{m}$ e, inicialmente, a sugestão foi inadequada. Outro aluno sugere a transformação correta, sem grandes discussões ou conflitos. Vale mencionar que o número de algarismos significativos e de casas decimais sequer são mencionados, e o aluno $A_{1}$ não demonstrou saber qual o valor da incerteza da medida de comprimento em metros. 
Então aquilo que a gente colocou tá certo? $\left[\mathrm{A}_{2} \mathrm{G}_{5}\right]$.

Não. Sim se colocar o polo aqui. $\left[\mathrm{A}_{1} \mathrm{G}_{5}\right]$.

Então "tava" certo. $\left[\mathrm{A}_{2} \mathrm{G}_{5}\right]$.

Primeiro "mano", a gente tem que passar essa massa aqui pra quilo, comprimento da baste é $50 .\left[\mathrm{A}_{1} \mathrm{G}_{5}\right]$.

É metros. Não "tá" em metro? [ $\left.\mathrm{A}_{3} \mathrm{G}_{5}\right]$.

Não. Coloca aí o 0 é metro. Tá 50 centímetros. $\left[\mathrm{A}_{1} \mathrm{G}_{5}\right]$.

0,05 ? $\left[\mathrm{A}_{3} \mathrm{G}_{5}\right]$.

Não. 0,5 metros. $\left[\mathrm{A}_{1} \mathrm{G}_{5}\right]$.

50 centimetros? $\left[\mathrm{A}_{3} \mathrm{G}_{5}\right]$.

Sim, sim, 0,51 não 0,501 mais ou menos 0,00000. $\left[\mathrm{A}_{1} \mathrm{G}_{5}\right]$.

Acho melhor deixar 0,5 ou 0,50? $\left[\mathrm{A}_{2} \mathrm{G}_{5}\right]$.

Também acho que é 0,50. Escrevi aqui do lado, tem espaço é 0,50 metros mais ou menos 0,05. $\left[\mathrm{A}_{1} \mathrm{G}_{5}\right]$.

Comprimento da mola sem carga. $\left[\mathrm{A}_{3} \mathrm{G}_{5}\right]$.

Posição da carga. Já me fala a massa que eu divido por mil e dá certo, 8,69 × 10 a -3 quilogramas. $\left[\mathrm{A}_{1} \mathrm{G}_{5}\right]$.

É interessante perceber que os alunos sugeriram e utilizaram a potência de dez para transformar a unidade de medida de massa de g para kg e não utilizaram o mesmo recurso quando foram transformar a unidade de medida do comprimento de $\mathrm{cm}$ para $\mathrm{m}$. A quantidade de algarismos significativos que deveriam representar as medidas é mencionada, mas não encontramos grandes conflitos e discussões nesse quesito, conforme ilustra a transcrição a seguir.

Coloca todos $\times 10$ a $-3 .\left[\mathrm{A}_{2} \mathrm{G}_{5}\right]$.

Coloca 97,8 $\times 10$ a -3, eu perdi um ponto na atividade de Física por causa disso do Moodle. Eram quatro, fir toda a conta deu 142, á eu coloquei 142 e ele queria 142,0.

$\left[\mathrm{A}_{1} \mathrm{G}_{5}\right]$.

Peso da haste é 959,32. [ $\left.\mathrm{A}_{2} \mathrm{G}_{5}\right]$.

Não. Calma. Não. "Mais" isso á tem que dividir em gramas tem que fazer. $\left[\mathrm{A}_{1} \mathrm{G}_{5}\right]$.

Todos as vezes 10 a -3 . 0,95932 quantos A.S.? $\left[\mathrm{A}_{2} \mathrm{G}_{5}\right]$.

Três. $\left[\mathrm{A}_{1} \mathrm{G}_{5}\right]$.

$0,96 ?\left[\mathrm{~A}_{2} \mathrm{G}_{5}\right]$.

Sim. Vezes 9,81. $\left[\mathrm{A}_{1} \mathrm{G}_{5}\right]$.

Não. Faz de novo vezes 9,81. $\left[\mathrm{A}_{3} \mathrm{G}_{5}\right]$.

Presta atenção ó. A gente fez o peso em gramas, vezes a gravidade deu um número. Se a gente fizer o peso em grama, vezes a gravidade, vezes 10 a -3 é igual a esse número, vezes 10 a $-3 .\left[\mathrm{A}_{2} \mathrm{G}_{5}\right]$.

Percebemos que para esses alunos, todos os números que aparecem em uma medida ou no cálculo de uma grandeza são algarismos significativos, independentemente se o algarismo zero estava à esquerda ou à direita da vírgula. Portanto, os conceitos de algarismo significativo e de casas decimais precisam ser melhor explicitados e trabalhados com esses estudantes. Outro aspecto importante a ser destacado é que as dúvidas, conflitos, dilemas e incertezas manifestadas pelos alunos desse grupo, que caracterizam as Tensões Representacionais, se 
referiam à identificação das incertezas a partir dos instrumentos, mostrando o isolamento dos discursos internos da Física (isolamento do discurso experimental em relação ao discurso teórico), enquanto as transformações das unidades de medidas estão relacionadas com o isolamento das disciplinas singulares (BERNSTEIN, 2003) como no caso da Física, Química, Geometria Analítica e Cálculo.

\section{Considerações Finais}

A análise dos dados apontou que os estudantes apresentaram as Tensões nos Discursos associadas com as representações dos dados obtidos durante um experimento de Física. Essas tensões observadas nas situações investigadas surgiram nos momentos em que os estudantes necessitaram representar as medidas com suas incertezas, quando transformaram as unidades de medidas e suas incertezas e ao registrarem o número de casas decimais e de algarismos significativos das medidas e de suas incertezas. Essas tensões tiveram como causa o isolamento dos discursos presente nas disciplinas singulares (BERNSTEIN, 2003).

Apesar das interações entre os alunos e destes com o professor possibilitarem o esclarecimento de dúvidas e a superação de alguns entraves na resolução do problema experimental proposto, elas não foram suficientes para evitar que as Tensões nos Discursos se manifestassem em experimentos realizados posteriormente. Assim, é importante que a atividade docente no ambiente experimental seja planejada adequadamente, tendo em vista que as situações apresentadas e a atuação do professor devem permitir minimizar as tensões nos discursos dos estudantes e potencializar a aprendizagem de Física, de modo que os experimentos sejam utilizados como recursos didáticos e pedagógicos capazes de contribuir com os processos de ensino e aprendizagem.

O isolamento dos discursos horizontal e vertical propostos por Bernstein (2000) foi identificado quando os alunos apresentavam dúvidas, dilemas, angústias e conflitos ao representar as incertezas das medidas, identificar a quantidade de algarismos significativos na medida e escrever corretamente o algarismo duvidoso utilizando um instrumento analógico. A minimização do isolamento nos discursos horizontal e vertical poderá ser conseguida na medida em que as atividades experimentais sejam realizadas com frequência ao longo da vida escolar dos alunos, tendo como um de seus objetivos a coleta de dados através de diferentes instrumentos de medidas.

$\mathrm{O}$ isolamento interno à Física referente ao discurso teórico versus experimental pode ser caracterizado na medida em que mesmo acompanhando as abordagens conceituais na disciplina teórica de Física, ministrada em paralelo aos experimentos realizados no laboratório didático, os alunos não foram capazes de empregar os conceitos estudados nas aulas teóricas na atividade experimental, apresentando incertezas, dilemas, dúvidas e angústias características da Tensão nos Discursos manifestada quando realizaram a representação dos dados obtidos ao longo do experimento. Assim, sugerimos que as atividades experimentais sejam planejadas adequadamente e desenvolvidas com frequência suficiente para que o discurso vertical seja assimilado pelos estudantes.

A utilização de roteiros fechados e estruturados pode ter contribuído para que os estudantes não tivessem condições favoráveis para refletir de maneira profunda e suficiente acerca das representações das medidas, o que poderia minimizar as Tensões nos seus Discursos. 
Além do aumento na frequência das atividades experimentais ao longo da vida escolar e acadêmica dos alunos, entendemos que a utilização de roteiros mais abertos e menos estruturados poderia possibilitar aos estudantes o envolvimento com discussões mais aprofundadas acerca da importância e significado das medidas, sobre a maneira correta de representar as medidas e suas incertezas, sobre a importância das transformações das unidades de medidas e de suas incertezas e, também, quanto à forma correta de representar as medidas e suas incertezas no que diz respeito ao número de casas decimais e de algarismos significativos.

Por fim, considerando que as Tensões nos Discursos identificadas e caracterizadas nesta pesquisa surgiram quando os alunos realizavam as atividades didáticas de Física com roteiros fechados e estruturados (MOREIRA; LEVANDOWSKI, 1983; RIBEIRO; FREITAS; MIRANDA, 1997), entendemos que se faz necessário o desenvolvimento de pesquisas que abordem a realização de experimentos envolvendo roteiros semiestruturados e não estruturados, especialmente as que mostram as transições entre os três tipos de roteiro (CAMPOS, 2010; CAMPOS; ARAÚJO, 2015), caminhando em direção a atividades de cunho investigativo, com o intuito de identificar e caracterizar outros tipos de Tensões nos Discursos dos discentes enquanto realizam as atividades experimentais em um laboratório didático.

\section{Agradecimentos}

Agradecemos a CAPES pelo financiamento desta pesquisa através da bolsa taxa concedida no início da realização das atividades, assim como os avaliadores deste artigo pela grande contribuição no seu aperfeiçoamento.

\section{Referências}

ARAÚJO, M. S. T.; ABIB, M. L. V. Atividades experimentais no ensino de física: diferentes enfoques, diferentes finalidades. Revista Brasileira de Ensino de Física, São Paulo, v. 2, n. 25, p. 176-194, 2003.

BAROLLI, E.; LABURÚ, C. E.; GURIDI, V. M. Laboratorio didáctico de ciencias: caminos de investigación. Revista Electrónica de Enseñanza de las Ciencias, Vigo, v. 9, n. 1, p. $88-110,2010$.

BERNSTEIN, B. A pedagogização do conhecimento: estudos sobre recontextualização.

Cadernos de Pesquisa, São Paulo, n. 120, p. 75-110, nov. 2003.

BERNSTEIN, B. Pedagogy, symbolic control and identity: theory, research, critique. New York: Rowman \& Littlefield, 2000.

BERNSTEIN, B. The structuring of pedagogic discourse - volume IV: class, codes and control. London: Routledge, 1990.

BERNSTEIN, B. Vertical and horizontal discourse: an essay. British Journal of Sociology Education, Abingdon, v. 20, n. 2, p. 157-173, 1999. 
BOGDAN, R.; BIKLEN, S. Investigação qualitativa em educação: uma introdução à teoria e aos métodos. Porto: Porto Editora, 1994.

BORGES, A. T. Novos rumos para o laboratório escolar de ciências. Caderno Brasileiro de Ensino de Física, Florianópolis, v. 19, n. 3, p. 291-313, 2002.

CAMPOS, L. S. Articulação entre modelagem matemática e experimentação: uma proposta para a construção de conhecimentos em física. 2010. 299 f. Dissertação (Mestrado) - Universidade Cruzeiro do Sul, São Paulo, 2010.

CAMPOS, L. S.; ARAÚJO, M. S. T. Articulação do ensino de física com o ensino de matemática através da modelagem matemática e das atividades experimentais. Revista Metáfora Educacional, Feira de Santana, n. 19, p. 21-52, dez. 2015.

CAMPOS, L. S.; ARAÚJO, M. S. T. Tensões conceituais e procedimentais nos discursos dos alunos durante as atividades experimentais de física. Revista de Ensino de Ciências e Matemática, São Paulo, 2019. (No prelo).

LABURÚ, C. E. Problemas abertos e seus problemas no laboratório de física: uma alternativa dialética que passa pelo discursivo multivocal e univocal. Investigações em Ensino de Ciências, Porto Alegre, v. 8, n. 3, p. 231-256, 2003.

MAINARDES, J.; STREMEL, S. A teoria de Basil Bernstein e algumas de suas contribuições para as pesquisas sobre políticas educacionais e curriculares. Teias, Rio de Janeiro, v. 11, n. 22, p. 1-24, ago. 2010.

MORAIS, A. M.; NEVES, I. P. A teoria de Basil Bernstein: alguns aspectos fundamentais. Práxis Educativa, Ponta Grossa, v. 2, n. 2, p. 115-130, 2007.

MOREIRA, M. A. Metodologia de pesquisa em educação. São Paulo: Livraria da Física, 2011.

MOREIRA, M. A.; OSTERMANN, F. Sobre o ensino do método científico. Caderno Catarinense de Ensino de Física, Florianópolis, v. 10, n. 2, p. 108-117, 1993.

MOREIRA, M. A.; LEVANDOWSKI, C. A. Diferentes abordagens ao ensino de laboratório. Porto Alegre: Editora da UFRGS, 1983.

OLIVEIRA, A. M. P. Modelagem matemática e as tensões nos discursos dos professores. 2010. 187 f. Tese (Doutorado em Ensino, Filosofia e História das Ciências) Universidade Federal da Bahia, Salvador, 2010.

OLIVEIRA, A. M. P.; BARBOSA, J. C. Modelagem matemática e situações de tensão na prática pedagógica dos professores. Bolema, Rio Claro, v. 24, n. 38, p. 265-296, abr. 2011.

RIBEIRO, M. S.; FREITAS; D. S.; MIRANDA, D. E. A problemática do ensino de laboratório de física na UEFS. Revista Brasileira de Ensino de Física, São Paulo, v. 19, n. 4, p. 444-447, dez. 1997.

SANTOS, L. L. C. P. Bernstein e o campo educacional: relevância, influências e incompreensões. Cadernos de Pesquisa, São Paulo, n. 120, p. 15-49, nov. 2003. 
SHALEM, Y. Sign, frame and significance: studying student teachers' reading of the particular. Journal of Education, Pietermaritzburg, n. 32, p. 49-80, 2004.

SILVA, L. A.; OLIVEIRA, A. M. P. A tensão da elaboração da situação-problema no planejamento do ambiente de modelagem matemática. In: SEMINÁRIO

INTERNACIONAL DE PESQUISA EM EDUCAÇÃO MATEMÁTICA, 5., 2012, Petrópolis. Anais [...] Rio de Janeiro: Sociedade Brasileira de Educação Matemática, 2012. Disponível em: < http://www.sbembrasil.org.br/files/v_sipem/PDFs/GT10/ CC02580726527_A.pdf>. Acesso em: 26 abr. 2019.

SILVEIRA, F. L.; OSTERMANN, F. A insustentabilidade da proposta indutivista de "descobrir a lei a partir de resultados experimentais". Caderno Brasileiro de Ensino de Física, Florianópolis, v. 19, n. esp., p. 7-27, 2002. 
